\title{
TAKTING THE SUSTAINABILITY OF CONSTRUCTION PROCESSES: AN ENVIRONMENTAL ASSESSMENT METHOD
}

\author{
Benjamin Slosharek ${ }^{1}$, Janosch Dlouhy ${ }^{2}$, Patricia Schneider-Marin ${ }^{3}$ and Werner \\ Lang $^{4}$
}

\begin{abstract}
The building sector is key to achieving global sustainability targets due to its significant resource consumption, associated emissions, and waste generation. Life cycle assessment (LCA) evaluates the environmental quality of buildings to identify improvement possibilities. However, current research activities limit their focus on a few life cycle phases, while the construction phase receives none to little attention. At the heart of the problem lies the lack of information about on-site processes and the lack of tools to evaluate the environmental quality of construction processes. The authors developed a conceptual framework to assess this aspect using an interdisciplinary approach. The proposed solution is based on two main methods, namely LCA and Takt Planning (TP). Based on literature research we identified the main categories for environmentally relevant in- and outputs of construction processes. This allows a structured, standardized, and scalable assessment of each single process step from an environmental perspective We anticipate this method to be a starting point for a holistic sustainability approach for construction process assessment. Further development of this framework aims to broaden the current environmental evaluation in the building sector and to improve both, the construction process and the building product from an environmental point of view.
\end{abstract}

\section{KEYWORDS}

Sustainability, takt planning (TP), life cycle assessment (LCA), lean construction (LC), process, theory.

\section{INTRODUCTION}

The construction industry can be held responsible for $36 \%$ of the global energy consumption and 39\% of the global emissions (IEA 2019). In addition, more than 50\% of total waste generation in Germany can be linked to the construction sector (UBA 2019). Due to this, the research issue of energy and resource efficient buildings becomes more and more important. Throughout the last two decades, the majority of research of

1 Junior Project Manager, KVL Bauconsult GmbH, +49 15773597610, benjamin.slosharek@kvlgroup.com, orcid.org/0000-0003-3935-8918

2 Lean Expert, BMW AG, +4915160171327, janosch.dlouhy@bmw.de, orcid.org/0000-0001-5954$\underline{9936}$

3 Research Fellow, Institute of Energy Efficient and Sustainable Design and Building, Technical University of Munich (TUM), patricia.schneider@tum.de, orcid.org/0000-0003-3728-5938

4 Professor, Institute of Energy Efficient and Sustainable Design and Building, Technical University of Munich (TUM), w.lang@tum.de, orcid.org/0000-0002-6593-8388 
sustainable and green buildings targeted the operational phase, i.e., optimizing and reducing the energy consumption and the related emissions. As the operational phase of the building constitutes only one part of the whole building life cycle, the consistent reduction of these emissions is not expedient for a holistic sustainable approach. Energy and emissions caused by the manufacturing of the building materials, the construction stage, and the deconstruction of a building are rarely seen in the sustainability assessment (Takano et al., 2014). Dependent on the energy standard of the building and the duration of the operational phase the shares of the embodied energy gain in importance compared to the energy consumption during the operational phase. Therefore a holistic approach to the sustainability assessment of a building should include all life cycle stages of a construction project (Wiik et al., 2017).

Decisions affecting the environmental quality of buildings mostly disregard the construction process, consisting of transportation (phase A4 per BS EN 15978) and the construction/installation (phase A5). There are hardly any valid data sets for the phase of construction (A5) as well as the deconstruction phase (C1) due to the infrequent consideration and the lack of understanding of the construction and deconstruction processes (Gantner et al., 2015). The individual character of each construction project and uncertainties in future scenarios lead to the presumption, that an analysis procedure based on standardized process sequences is difficult to realize (Wiik et al., 2017). Decoding the construction site is perceived as too burdensome, especially considering the overall benefits (Torres, 2014). This leads to the exclusion of the construction phase from environmental assessments, because transparency with regard to construction processes is too hard to achieve. At the same time, the impact of these phases is assumed to be lower compared to other life cycle phases.

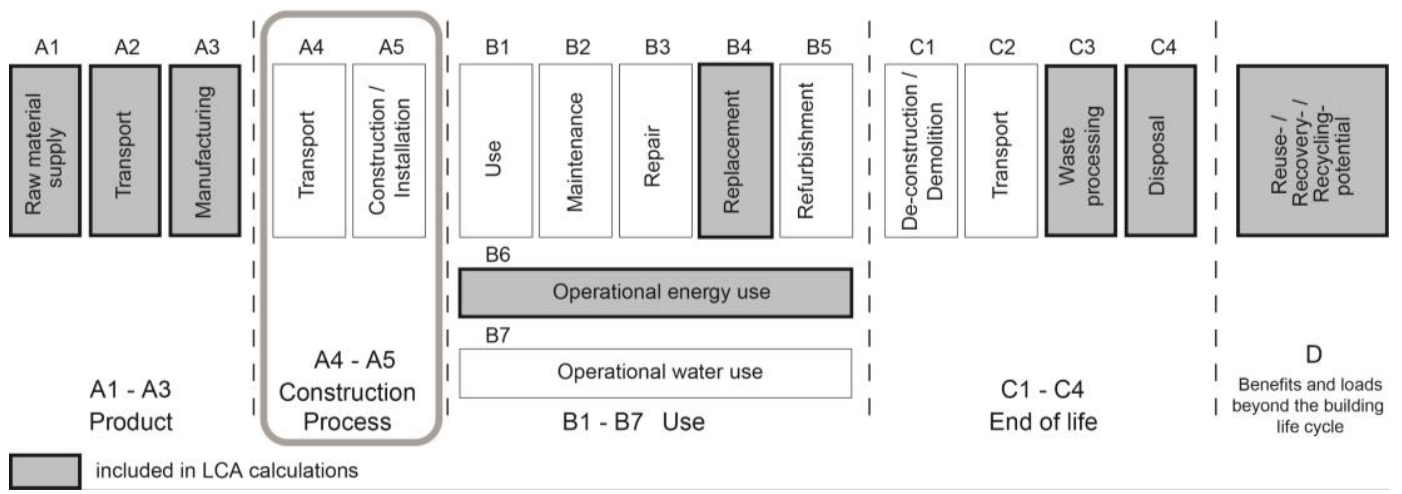

Figure 1: Life cycle phases of a building (BS EN 15978)

Lean Construction (LC) aims to maximize customer value by minimizing waste in the construction process (GLCI, 2019). In order to analyze waste in processes, the value chain has to be as transparent as possible. The LC approach can therefore provide a transparent and stable foundation for environmental assessments of the process sequences. As a method of LC, Takt Planning and Takt Control (TPTC) pursues to define standardized and harmonized process sequences and thereby to ensure the flow and stability of the ongoing work steps during the construction process (Dlouhy et. al., 2016).

With the process sequences, LC and TPTC thus offer a transparent basis for quantifying the different dimensions of an individual work step on the construction site. The idea of the proposed framework is to link these process elements with environmental parameters and thus to make the process sequences accessible from an environmental point of view. There are existing methods that quantify the environmental impact of a 
process. Faulkner and Badurdeen (2014) developed a similar approach for manufacturing, called sustainable value stream mapping. Within the construction sector, such an assessment of environmental sustainability can rarely be found in recent research activities (Fu et al., 2015; Rosenbaum et. al., 2014), as the adaptation of production methods in this sector is still in its early stages.

\section{THEORETICAL BACKGROUND}

\section{LEAN CONSTRUCTION AND SUSTAINABILITY}

LC focuses primarily on increasing productivity and thus predominantly on economic parameters. The individual steps within a process, which are essential for delivering value, are deciphered, and the flow efficiency and productivity can be increased.

LC therefore takes a process-oriented view when considering the life cycle phases of the building: The process and not the product is the main focus of these studies (Ballard et al., 2007). LC follows the approach of eliminating any waste in processes during a building's life cycle (Ballard et al., 2007). Resources in this context represent only means that are needed for a process to take place. Thus, according to LC, waste of financial resources, human resources, materials or time should be prevented (Koskela, 1992).

The sustainable building approach, on the other hand, is based on the tripartite nature of sustainability in terms of environmental, economic, and social matters. For example, the triple bottom line divides the broad subject area into three basic domains: the (1) social domain, the (2) environmental domain, and the (3) economic domain (Elkington, 2013) Another variation of the division sees the economic system as a subsystem of the social system, which in turn is a subsystem of the environmental system (Cato, 2009, p. 37). Following this approach, the concept of green building extends the classic paradigm of management between quality, time, and cost to include global factors such as reduction of resource depletion, reduction of emissions, and protection of natural land areas (Huovila and Koskela, 1998)

Depending on how and in what form LC is used in a construction project, the effects on overall sustainability can vary (Nahmens and Ikuma, 2012). The avoidance of waste can be identified as the most frequently cited commonality between the two philosophies based on several research reports (Carvajal-Arango et al., 2019). The dimensions of waste are defined differently. While sustainable buildings aim to minimize unnecessary emissions and resource waste in the form of material and energy consumption (Kibert, 2016), LC focuses on economic factors.

\section{Synergies in Practical Application}

Carvajal-Arango et al. (2019) conducted a literature review to investigate the relationships between LC and sustainability with regard to the construction phase of a building. The authors analyzed different LC methods and their impact on the overall sustainability of building construction. The authors found that the most common reasons for implementing LC could be attributed to economic motivation, whereas, positive effects on the environmental impact of the construction phase emerged as well. Demanding a holistic assessment, the authors advocate a standardized sustainability assessment method for the construction phase of LC projects additionally to existing economic indicators.

Fu et al. (2015) show how LC methodologies, in terms of process optimization, can help to improve sustainability during the construction phase. The authors analyzed 
individual processes on the construction site and compared several process variants based on environmental impacts. By using the LCA method the authors accurately allocate the environmental impacts to the respective input categories of the process: energy, transportation, machinery, and materials are identified as the main categories which can cause environmental impacts. The researchers use greenhouse gas emissions to quantify these impacts. Emissions, especially from materials and machine use, could be reduced by such a process analysis. At the same time, however, improvements were also shown on an economic basis: time and money were saved, working conditions were improved, and potential safety risks for employees were reduced. The authors recommend a stronger link between LC and LCA, especially if both can be carried out on the basis of standardized processes.

\section{CONCEPTUAL FRAMEWORK FOR SUSTAINABILITY ASSESSMENT OF CONSTRUCTION PROCESSES}

\section{METHODOLOGY}

The development of the framework follows two perspectives: the process perspective of the LC approach and the perspective of sustainability in the sense of the environmental impact of the process steps. The aim of this framework is to visualize and assess the environmental impacts caused by construction processes by integrating the environmental dimension into the TP method.

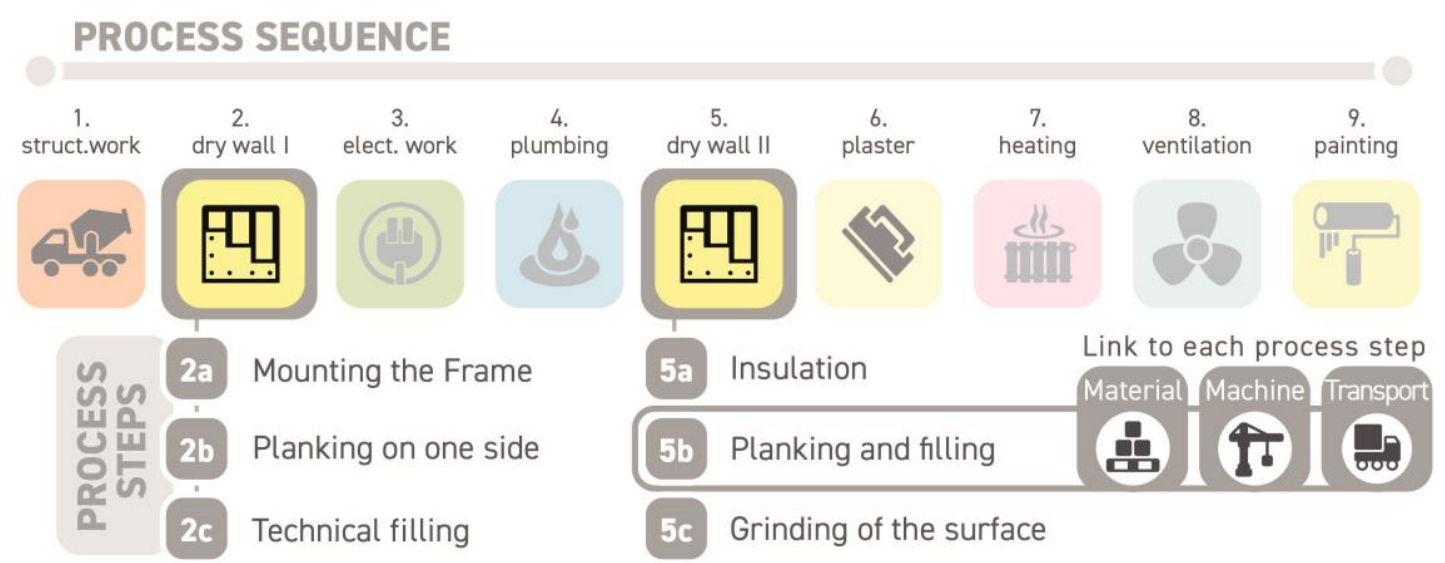

Figure 2: Example sequence with application of the resource categories to the work steps for dry wall construction.

For the process-related view, the method of TPTC is used, in which the process steps of the construction site are arranged into work packages and harmonized "wagons" (Dlouhy et al., 2016). The standardization of the process sequences makes the individual work steps scalable (Haghsheno et al., 2016). For the environmental evaluation of each process step, the input-output life cycle assessment (LCA) method is used. In this assessment, the expenditures (inputs) and the resulting impacts (outputs) of a process or a product are examined and analyzed in detail in terms of environmental sustainability. The combination of the two fields of research should ease a quantification of the environmental impact caused by the process steps.

LCA applied in construction usually considers building parts composed of building elements (König et al. 2009) consisting of material layers. This subdivision is necessary 
for the assessment of potential environmental impacts, since only at the material level one can assign the characteristic values for environmental impacts via databases. For example, a drywall without any installation should be divided into the material-layers (1) frame, (2) insulation, (3) planking, and (4) paint for an assessment. The process view follows a different approach: the construction process analysis focuses on the work packages of the trades, which is why the drywall is classified by the perspective of the trades: Position (1) to (3) are provided by the drywall construction trade and position (4) is provided by the painting work trade.

Assessing the environmental impacts of construction processes requires the combination of the material/product perspective with the process perspective. In order to achieve this, the construction process must be defined to such an extent that materials and products can be clearly assigned. In this case, the proposed environmental process analysis considers the work packages of the respective trades with their individual steps. In Figure 2 the work packages (Number 2 and 5) and process steps (2a-2c; 5a-c) necessary for a drywall construction are highlighted within a sample sequence. This subdivision can logically be related to the TPTC method, as the individual work steps are systematically broken down as following: TP follows the 3-level model with the macro, norm and micro level. The micro level is the most detailed level of a construction process and contains information on each individual process step (Dlouhy et al., 2016). According to the logic of the framework, environmental parameters are assigned to each step of the construction process as a basis for environmental impact calculation. This procedure follows a bottomup approach: The smallest unit of a system is analysed to draw general conclusions for the whole.

Table 1: Categories for assessing the environmental impacts of construction sites, BS EN 15978

\begin{tabular}{cc}
\hline Phase A4 - Transport & Phase A5 - Assembly on Site \\
\hline Material Transports, Gate to Site & Assembly of building components \\
Transport of Construction Equipment to Site & $\begin{array}{c}\text { Installation of building materials, auxiliary } \\
\text { materials included }\end{array}$ \\
Material losses during transportation & Air conditioning of site or material storage \\
Optional: Transport of workers to site & \\
\hline
\end{tabular}

\section{RESOURCE CATEGORIES: ENVIRONMENTALLY RELEVANT INPUTS OF CONSTRUCTION PROCESSES}

Following the LCA method, relevant inputs and outputs have to be defined for each individual step of the process. The activities on the construction site consume time, energy, material, labor and financial resources in order to create value, i.e., the building itself. For the calculation of environmental parameters it is necessary to define inputs and outputs, which are linked to environmental sustainability. Previous studies targeting environmental assessments of building sites used differing approaches:

Kellenberger and Althaus (2009) mainly consider the necessary auxiliary materials for the construction of a building component. Takano et al. (2014) list transportation and logistics expenses as a main driver of potential environmental impacts during the construction of buildings. Wiik et al. (2017) consider a relatively broad system boundary of the construction phase and link the main environmental impacts to usage of construction machinery, on-site electricity consumption, transportation, and the general 
installation of materials. Fu et al. (2015) identify in their case study project four main causes or emissions: energy, materials, machinery, and transportation. Thus, the categories of (1) material, (2) machinery, and (3) transportation can in general be derived from these research reports. Similar breakdowns can be found in the international standard for environmental assessment approaches. DIN EN 15978:2012-10 (2012) as shown in Table 1.

In summary, the first main element of the proposed framework is deduced from the research reports: The resource categories. These are represented by (1) materials, (2) machinery, and (3) transportation. Based on these subdivisions, it should be possible to define the main expenses from an environmental perspective for a process step. These categories can be seen as the environmentally relevant inputs of a single process. The framework should offer the possibility to link exact values to each process step, e.g. for material quantity, construction machine hours, or transport distances.

\section{IMPACT CATEGORIES: ENVIRONMENTALLY RELEVANT OUTPUTS OF Construction Processes}

All process steps have differentiated amounts of environmental impacts due to the respective types of expenditure. These are divided into different impact categories for the environmental impact assessment step of LCA. The focus of the framework is on the construction sector, for which GWP (global warming potential) and AP (acidification potential) are deemed the most relevant impact indicators (Ismaeel, 2018). Additionally, the PENRT (total use of nonrenewable primary energy resources) and the amount and type of material waste are included in the environmental assessment framework of the process steps. In summary, the categories (1) PENRT, (2) GWP and AP, and (3) Waste represent the second core element of the framework: the impact categories. From an environmental point of view, they represent the relevant outputs of the process apart from the building component itself. In strict LCA methodology, primary energy is accounted for as input and therefore as part of the resource categories. Similarly, in LCA, waste is considered an output category. However, within the developed framework, PENRT and waste are treated as an assessment index for the construction process steps and are thus considered impact categories.

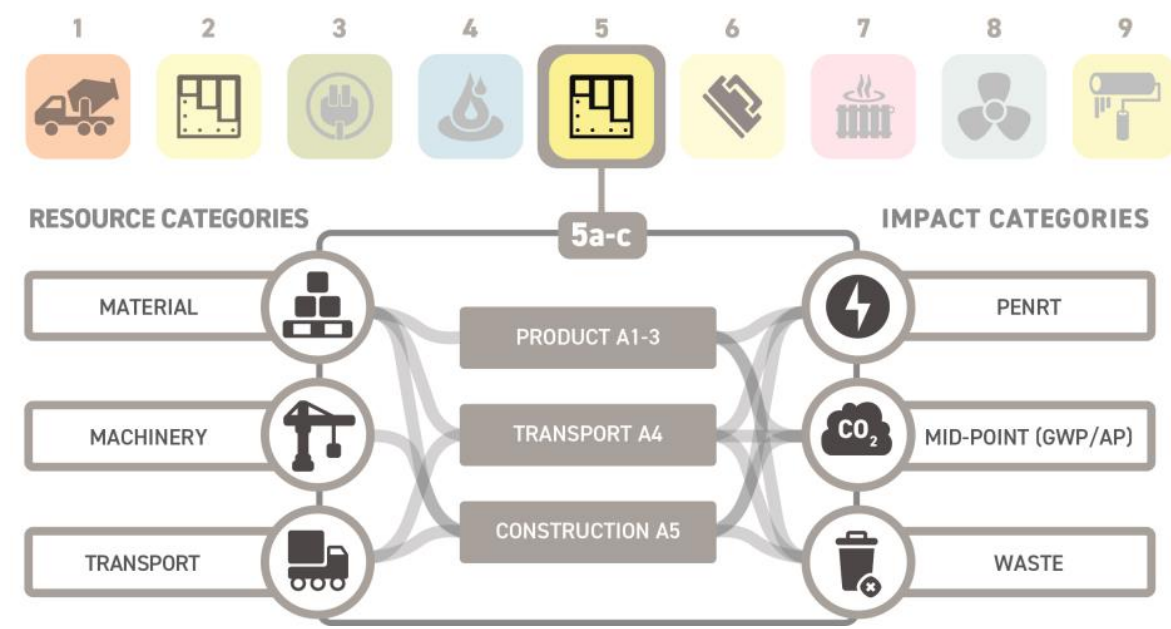

Figure 3: framework for the environmental assessment of construction processes with in- and outputs 
To summarize, as shown in Figure 3, the three resource categories represent the relevant expenditures from an environmental perspective, which are necessary for the process to take place and create the added value. The impact categories, on the other hand, provide information about the environmentally relevant impacts of a process step.

\section{RESUlts ANd Potential OF THE Framework}

Provided that the framework is successfully implemented in the TPTC, the construction processes can be analyzed in different ways simultaneously, as shown in Figure 4. It seems reasonable to differentiate the calculated results of the framework into the product view and process view, as described by Ballard et al. (2007).

Table 2: Exemplary results of the framework application to the work package 5

\begin{tabular}{|c|c|c|c|c|}
\hline Description & $\begin{array}{l}\text { Resource } \\
\text { Category }\end{array}$ & $\begin{array}{l}\text { Life cycle } \\
\text { Phase }\end{array}$ & $\begin{array}{c}\text { Impact } \\
\text { Category GWP } \\
\text { [kg-CO2e] }\end{array}$ & $\begin{array}{c}\text { Product } / \\
\text { Process } \\
\text { View }\end{array}$ \\
\hline Plasterboard and insulation & Material & A1-3 & 7.37 & Product \\
\hline $\begin{array}{l}\text { Trasportation Gate to Site } \\
\text { (Plasterboard and Insulation) }\end{array}$ & Transport & A4 & 0.43 & Process \\
\hline Filler (Auxillary material) & Material & A5 & 0.21 & Process \\
\hline $\begin{array}{l}\text { Materiallosses due to cuts } \\
\text { (Plasterboard and Insulation) }\end{array}$ & Material & A5 & 1.47 & Process \\
\hline $\begin{array}{c}\text { Usage of table saw and cordless } \\
\text { screwdriver }\end{array}$ & Machinery & A5 & 0.84 & Process \\
\hline
\end{tabular}

Table 2 shows results for the application of the method to the drywall process shown in figure 3 , divided by the process and product view. Accordingly, the product view refers to phase A1-3 where the ideal amount of material within the final product is being assessed. The process view complements these considerations with environmentally relevant impacts during phases A4-5, which, as explained in the introduction, are currently rarely mapped. The results show $7.37 \mathrm{~kg}-\mathrm{CO}_{2} \mathrm{e}$ for the impacts of the product view, which is equivalent to $71 \%$ of the impacts of the work package, whereas $2.95 \mathrm{~kg}$ $\mathrm{CO}_{2} \mathrm{e}$ or $29 \%$ are related to the process view. Based on the developed framework each impact can be related to the life cycle phases, the source of the impact, and whether it is related to the product or process view. The exemplary results refer to $1 \mathrm{~m}^{2}$ of drywall construction.

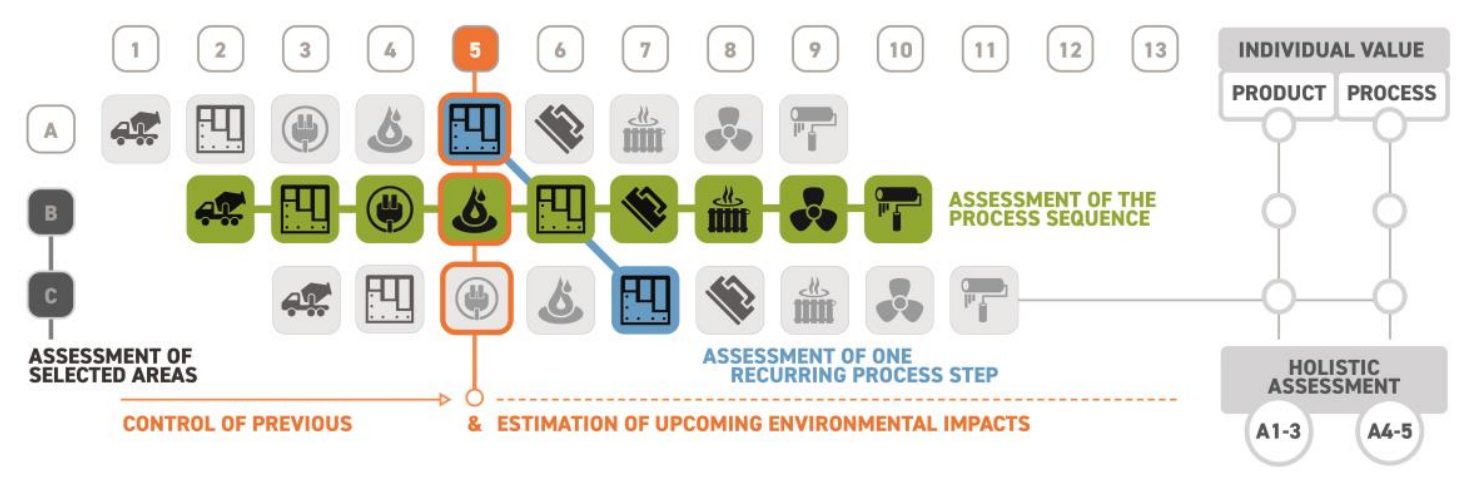

Figure 4: Analysis options when applying the framework to Takt Planning 
As a holistic approach, the method of TPTC within LC offers several potentials for synergies with the developed framework. TPTC is based on the approach of generic process sequences and maps the construction project based on recurring takt areas with identical work packages within the taktplan (Binninger et al., 2017) This method of process sequences enables the scalability of the processes (Haghsheno et al., 2016) and therefore the scalability of environmental impacts calculated with the framework.

Furthermore, based on the taktplan, not only the spatial and thus qualitative, but also the temporal dimension of the process can be related to its environmental impacts. The environmental factors can be used as a performance indicator alongside economic factors to evaluate the construction progress during an ongoing project.

\section{DISCUSSION}

The approach of combining LCA and TP to analyze the environmental sustainability of construction processes is considered a useful and detailed methodology. It can be used to map material and energy flows, transport expenditures, and emissions or resource depletion from a processual point of view.

The framework extends the current focus of the LC philosophy, which currently aims for high productivity and high quality (Kaiser, 2013; GLCI e.V., 2019). Considering environmental and process quality at the same time can be beneficial and obstructive at the same time. On the one hand, this adds a new dimension to the existing analysis of processes and generates more insights into the overall performance of the process. On the other hand, when improving the process, environmental and economical goals can be in conflict. Therefore one has to prioritize one dimension regarding possible trade-offs.

Potential limitations in the framework can also be identified. The resource categories convey a clear structure but can be too general for the assessment of every single process step. Thus a relevant set of subcategories of the resource categories should be defined by further research. Furthermore, not every source of environmental impact can be linked to a single process step, like site facilities or lifting equipment. Accordingly, the results of the framework so far are limited to resource categories that can be linked to a single work package directly. Finally, the applicability to construction projects without TPTC is limited because there are no standardized sequences to assess. This might be overcome by the assessment of multiple TPTC projects with the proposed method when sound knowledge about the main processes on every construction site can then be derived and applied to projects without TPTC. All of the mentioned limitations can have a significant impact to the scalability of the method and need to be addressed by studies in the future.

Generally speaking, the extension of current environmental analyses with a process view requires a change in thinking: Alongside the materials and the quantification of what the building consists of, one clearly needs transparency to understand the process and how the building is constructed. Both product and process assessment should be quantified separately and in detail. Otherwise, comparability to other scientific studies suffers since standardized construction processes or work packages of single trades have rarely been taken into account for environmental evaluations so far.

\section{CONCLUSION}

Climate change is the greatest global challenge in the foreseeable future. As one of the main greenhouse gas emitters worldwide, the construction sector has a responsibility to find solutions. The environmental waste during construction is neither surveyed nor 
evaluated. Due to continuous optimization of the operational phase, the consideration of the Product (A1-3) and Construction Process (A4-5) phases according to BS EN 15978 become increasingly relevant for a holistic sustainability assessment. The framework presented in this paper enables analysis and visualization of emissions and environmentally relevant waste of construction processes. This is possible due to TP, even without expert knowledge about LCA. Results are determined at the point of value creation, the work process, utilizing the impact categories. Optimization can thus take place directly and measurably. A consideration of the environmental waste on building sites, without the LC approach of TP, appears very complex and error-prone. The transfer of construction processes into a construction production using TP shows its scalable and data-driven capabilities, especially when assessing environmental quality through the described framework.

Furthermore, the use of digital tools and databases for emissions, waste, and traditional TP parameters should allow for better applicability of more and more complex data structures when assessing the processes in practice. The authors see an opportunity for a holistic and integral perspective in the planning of construction processes as well as in the selection of construction products through the proposed environmental assessment of takted processes. The possibility to evaluate and compare the environmental efficiency of building processes, building materials, and the overall building construction has the potential to lead to new conclusions and thus novel solutions.

\section{REFERENCES}

Ballard, G., Tommelein, I., Koskela, L., and Howell, G. (2007). "Lean construction tools and techniques." Design and Construction, Routledge, 251-279.

Binninger, M., Dlouhy, J., and Haghsheno, S. (2017). "Technical Takt Planning and Takt Control in Construction." Proc. 25th Ann. Conf. of the IGLC.

Carvajal-Arango, D., Bahamón-Jaramillo, S., Aristizábal-Monsalve, P., VásquezHernández, A., and Botero, L. F. B. (2019). "Relationships between lean and sustainable construction: Positive impacts of lean practices over sustainability during construction phase." Journal of Cleaner Production, Elsevier, 234, 1322-1337.

Cato, M. S. (2009). Green Economics: An Introduction to Theory, Policy and Practice. Earthscan.

Chastas, P., Theodosiou, T., and Bikas, D. (2016). "Embodied energy in residential buildings-towards the nearly zero energy building: A literature review." Building and Environment, Elsevier, 105, 267-282.

BS EN 15978:2011. (2011). Sustainability of construction works. Assessment of environmental performance of buildings. Calculation method. Standard, BSI, London.

Dlouhy, J., Binninger, M., Oprach, S., and Haghsheno, S. (2016). "Three-level method of Takt Planning and Takt control-A new approach for designing production systems in construction." Proc. 24th Ann. Conf. of the IGLC.

Elkington, J. (2013). "Enter the Triple Bottom Line." The Triple Bottom Line, Routledge, 23-38.

Faulkner, W., and Badurdeen, F. (2014). "Sustainable Value Stream Mapping (SusVSM): methodology to visualize and assess manufacturing sustainability performance." Journal of cleaner production, Elsevier, 85, 8-18.

Fu, F., Sun, J., and Pasquire, C. (2015). "Carbon emission assessment for steel structure based on lean construction process." Journal of Intelligent \& Robotic Systems, Springer, 79(3-4), 401-416. 
Gantner, J., Wittstock, B., and Lenz, K. (2015). EeBGuide Guidance Document Part B: Buildings. Operational guidance for life cycle assessment studies of the Energy Efficient Building Initiative. Fraunhofer Verlag.

GLCI e.V. (2019). Lean Construction - Begriffe und Methoden. German Lean Construction Institute - GLCI e. V. c/o KIT Institut für Technologie und Management im Baubetrieb.

Haghsheno, S., Binninger, M., Dlouhy, J., and Sterlike, S. (2016). "History and Theoretical Foundations of Takt Planning and Takt Control." Proc. 24th Ann. Conf. of the IGLC.

Huovila, P., and Koskela, L. (1998). "Contribution of the Principles of Lean Construction to Meet the Challenges of Sustainable Development." 6th Ann. Conf. of the IGLC.

IEA. (2019). Global Status Report for Buildings and Construction 2019 - Analysis - IEA. International Energy Agency.

Ismaeel, W. S. (2018). "Midpoint and endpoint impact categories in Green building rating systems." Journal of Cleaner Production, Elsevier, 182, 783-793.

Junnila, S., Horvath, A., and Guggemos, A. A. (2006). "Life-cycle assessment of office buildings in Europe and the United States." Journal of Infrastructure systems, ASCE, 12(1), 10-17.

Kaiser, J. (2013). Lean Process Management in der operativen Bauabwicklung. Institut für Baubetrieb.

Kellenberger, D., and Althaus, H.-J. (2009). "Relevance of simplifications in LCA of building components." Building and Environment, Elsevier.

Kibert, C. J. (2007). "The next generation of sustainable construction." Building Research \& Information, Taylor \& Francis, 35(6), 595-601.

Klöpffer, W., and Grahl, B. (2014). Life cycle assessment (LCA): a guide to best practice. WILEY-VCH Verlag.

König, H., Kohler, N., Kreißig, J., and Lützkendorf, T. (2009). Lebenszyklusanalyse in der Gebäudeplanung. Detail Green Books, DeGruyter, Berlin.

Koskela, L. (1992). Application of the new production philosophy to construction. Stanford University Stanford.

Koskela, L. (2006). "Foundations of concurrent engineering." Concurrent Engineering in Construction Projects, Routledge, 26-43.

Nahmens, I., and Ikuma, L. H. (2012). "Effects of lean construction on sustainability of modular homebuilding." Journal of Architectural Engineering, ASCE, 18(2)

Rosenbaum, S., Toledo, M., and Gonzalez, V. (2014). "Improving Environmental and Production Performance in Construction Projects Using Value-Stream Mapping: Case Study." Journal of Construction Engineering and Management, 140

Takano, A., Pittau, F., Hafner, A., Ott, S., Hughes, M., and De Angelis, E. (2014). "Greenhouse gas emission from construction stage of wooden buildings." International Wood Products Journal, Taylor \& Francis, 5(4), 217-223.

Torres, N. (2014). "Study of sustainability opportunities during construction." PhD Thesis, University of Texas, Austin.

UBA. (2019). "Abfallaufkommen | Umweltbundesamt.” Umweltbundesamt.

Wiik, M. R. K., Sørensen, \AAse Lekang, Selvig, E., Cervenka, Z., Fufa, S. M., and Andresen, I. (2017). "ZEB Pilot Campus Evenstad. Administration and educational building. As-built report." ZEB Project report, SINTEF akademisk forlag. 